\title{
Concealed Ovulation May Have Driven Breast Development from Puberty and Body Hair Loss in Humans
}

\author{
Sooil Kim, Young Ho Lee*
}

Department of Anatomy, College of Medicine, Chungnam National University, Daejeon, Korea

\author{
DOI: $10.36348 /$ sijap.2020.v03i01.002 \\ | Received: 04.01.2020 | Accepted: 19.01.2020 | Published: 25.01.2020 \\ *Corresponding author: Young Ho Lee
}

\section{Abstract}

There are many theories about concealed ovulation, breast development from puberty, and body hair loss in human evolution. We propose a novel theory on the association between concealed ovulation and breast development and body hair loss in human evolution. Concealed ovulation may have caused breast development from puberty and body hair loss in humans.

Keywords: Concealed ovulation, breast development, body hair loss, Sexual selection, Natural selection.

Copyright @ 2020: This is an open-access article distributed under the terms of the Creative Commons Attribution license which permits unrestricted use, distribution, and reproduction in any medium for non-commercial use (NonCommercial, or CC-BY-NC) provided the original author and source are credited.

\section{INTRODUCTION}

There are many theories about concealed ovulation, breast development from puberty, and body hair loss in human evolution, but all of them remain controversial.

The main hypotheses for body hair loss in humans are as follows: i) to control body temperature on the hot savannah [1], ii) to adapt to a lifestyle of foraging for food in shallow waters [2], iii) to eliminate ectoparasites on the body $[3,4]$, and iv) to display smooth and clear skin for sexual selection purposes, as posited by Charles Darwin [5].

There are two hypotheses regarding breast volume development (enlargement) from puberty, aside from lactation. First, enlargement of the breasts via fat deposition, along with the development of the buttocks, allows for energy conservation to prepare for a long period of growth and the energy demands of a large brain, and the difficulty in regularly obtaining enough food [6]. Second, enlarged breasts are a type of sexual signalling to males. This hypothesis may be based on the mammary glands needed for breast feeding account for only one-third of the total volume of the breast [7].

\section{THE HYPOTHESIS}

We propose that concealed ovulation may have driven breast development from puberty and body hair loss in humans, which may help to solve the puzzles of human evolution.

\section{Evaluation of the hypothesis}

The weaknesses of the previous hypotheses for body hair loss are as follows. For the first hypothesis, body hair loss does not allow adaptation to temperature changes between day and night. There are few terrestrial animals that have lost body hair in Africa, and there are special evolutionary reasons for those that have. For example, elephants have lost their body hair because hair cannot grow in skin with a very thick epidermis. In humans, it is not reasonable for hair loss to be more severe in females than in males, who frequently hunted outside in Africa. For the second hypothesis, our ancestors were terrestrial animals. Their habitat was fundamentally on land, not in shallow waters. For the third hypothesis, other primates currently thrive while harbouring ectoparasites. It is estimated that our ancestors may have started wearing clothing approximately 50,000 years ago, whereas their body hair loss may have occurred more than one million years ago $[8,9]$. For the fourth hypothesis, there is not yet a reasonable explanation as to why evolutionary pressure for sexual (mating) signalling would be higher in humans than in other terrestrial animals.

The weaknesses of the previous hypothesis for breast development from puberty are as follows. There are no other terrestrial animals with enlarged breast volume from puberty, outside the period of lactation. Therefore, the first hypothesis associated with energy conservation may not be plausible. The second 
hypothesis related sexual signalling may be possible; however, there is no reasonable explanation for evolutionary pressure for sexual selection.

There are also many hypotheses explaining concealed ovulation in humans. However, the reason for concealed ovulation in humans is beyond the scope of this paper, and importantly, our ancestors had concealed ovulation signals, unlike other terrestrial animals.

Many terrestrial animals transmit ovulation signals using pheromones via the olfactory system. However, most primates transmit ovulation signals via visual cues, such as swelling of the buttocks in females. Humans have neither olfactory nor visual cues for ovulation signalling. The vomeronasal organ for olfactory ovulation signalling has disappeared in humans. There are no vestiges of visual ovulation signalling in the buttocks or other parts of the human body. This suggests that the system for visual ovulation signalling never developed in our ancestors during phylogenetic separation from other primates.

Ovulation signalling is very important for reproductive success. Concealed ovulation may have resulted in evolutionary pressure for continuous sexual (mating) signalling to replace ovulation signalling. Breast development (enlarged breast volume) from puberty, outside of lactation, is a strange phenomenon. The breast is an important reproductive organ. Enlarged breasts may be considered a good signal for breast feeding ability and reproductive success. Therefore, breast development from puberty may have become a sexual signal, instead of ovulation signalling.

Although breast development from puberty may have become a sexual signal, body hair may have blocked this sexual signal, like wearing clothing does today. Therefore, the evolutionary pressure for breast exposure and smooth and clean skin may have developed after the evolution of breast development from puberty. This evolutionary pressure may have led to body hair loss in females. Consequently, the genes for hair loss in females were passed on to males, and males also became naked. This hypothesis feasibly explains why hair loss is more severe in females than in males.

Hair development and eccrine sweat gland development have an inverse correlation: hair loss increases eccrine sweat gland development [10]. Therefore, body hair loss accompanied by an increased number of sweat glands may have helped our ancestors regulate their body temperature on the hot savannah. The fact that body hair loss is not suitable for adapting to temperature changes between day and night may have been overcome by making fires and wearing clothing. Body hair loss may also have contributed to fitness for living near shallow waters such as rivers, and eliminating ectoparasites. Nakedness in Homo sapiens may thus have originated due to sexual selection, and then accelerated due to natural selection.

In conclusion, concealed ovulation may have caused breast development from puberty and body hair loss in humans (Fig. 1).

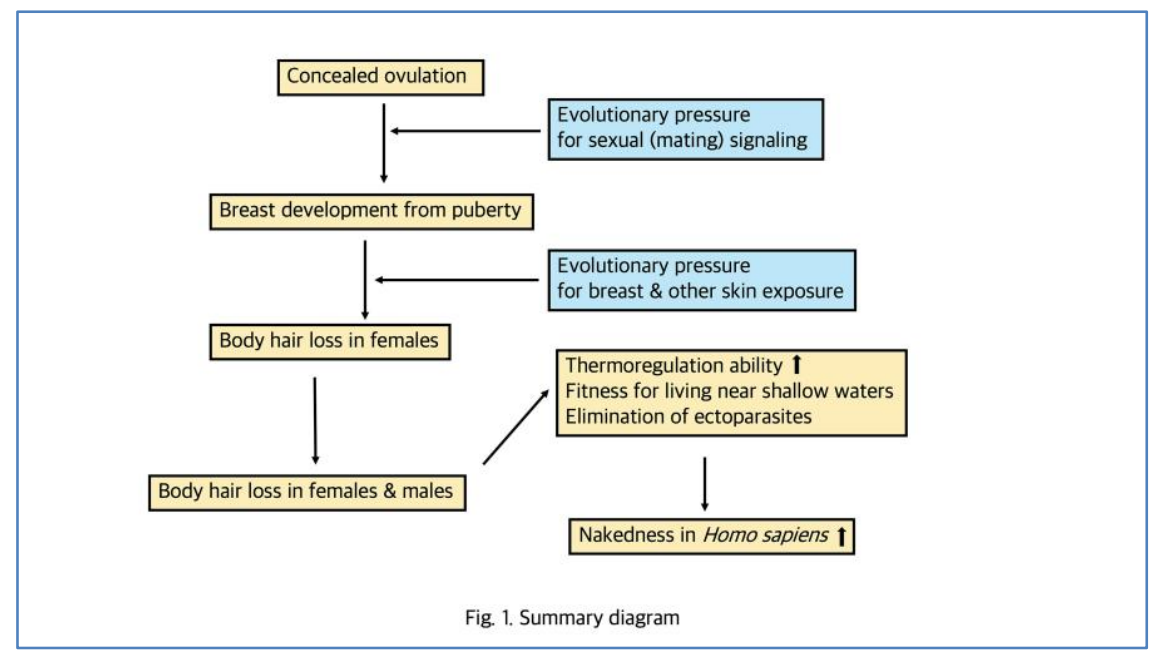

Fig-1

\section{Conflict of interest}

Authors declare that there is no conflict of interest in this study.

\section{REFERENCES}

1. Ruxton, G. D., \& Wilkinson, D.M. (2011). Avoidance of overheating and selection for both hair loss and bipedality in hominins. Proceedings of the National Academy of Sciences of the United States, 108(52):20965-20969.

2. Wrangham, R., Cheney, D., Seyfarth, R., \& Sarmiento, E. (2009). Shallow-water habitats as sources of fallback foods for hominins. American 
Journal of Physical Anthropology, 140(4): 630642.

3. Pagel, M., \& Bodmer, W. (2003). A naked ape would have fewer parasites. Proceedings Biological Sciences, 270:S117-S119.

4. Rantala, M. J. (1999). Human nakedness: adaptation against ectoparasites? International Journal of Parasitology, 29(12):1987-1989.

5. Darwin, C. (2018). The descent of man and selection in relation to sex. Ann Arbor, Hardpress Publishing.

6. Cant, J. G. H. (1981). Hypothesis for the Evolution of Human Breasts and Buttocks. American
Naturalist, 117(2) 199-204.

7. Morris, D. (2005). Naked ape. London, Vintage Publishing.

8. Kittle, R., Kayser, M., \& Stoneking, M. (2003). Molecular evolution of Pediculus humans and the origin of clothing. Current Biology, 13(16):14141417.

9. Rantala, M. J. (2007). Evolution of nakedness in Homo sapiens. Journal of Zoology, 273:1-7.

10. Lu, C. P., Polak, L., Keyes, B. E., \& Fuchs, E. (2016). Spatiotemporal antagonism in mesenchymal-epithelial signaling in sweat versus hair fate decision. Science, 354(6319). 